\title{
Diagnosis dan Tata Laksana Neonatus dari Ibu Hamil Tuberkulosis Aktif
}

\author{
Bobby S Dharmawan, Darmawan B Setyanto, Rinawati $R$
}

\begin{abstract}
Tuberkulosis (TB) pada kehamilan selain dapat mengenai ibu juga dapat menular pada bayi baik intrauterin, saat persalinan, maupun pasca natal. Kejadian TB kongenital selama persalinan sangat jarang. Gejala klinis TB pada neonatus sulit dibedakan dengan sepsis bakterial umumnya dan hampir semua kasus meninggal karena keterlambatan diagnosis. Manifestasi klinis TB kongenital dapat timbul segera setelah lahir maupun dalam beberapa hari. Gejala yang paling sering ditemukan adalah distres pernapasan, hepatosplenomegali, dan demam. Tata laksana TB pada neonatus mencakup beberapa aspek yaitu ibu, bayi yang dilahirkan dan lingkungan keluarga. Untuk diagnosis dan tata laksana diperlukan pemeriksaan klinis dan penunjang berupa pemeriksaan patologi dari plasenta darah v.umbilikalis, foto toraks, bilas lambung serta evaluasi uji tuberkulin secara berkala. Deteksi dini TB pada neonatus dan penanganan yang baik pada ibu dengan TB aktif akan memperkecil kemungkinan terjadinya TB perinatal.
\end{abstract}

Kata kunci: tuberkulosis, transmisi perinatal, profilaksis

T 1 uberkulosis merupakan masalah kesehatan di dunia. ${ }^{1}$ Berdasarkan laporan WHO, Indonesia menempati urutan ketiga terbesar angka kejadian TB di dunia setelah Cina dan India. ${ }^{2}$

Tuberkulosis pada kehamilan merupakan masalah tersendiri karena selain mengenai ibu, juga dapat menulari bayi yang dikandung atau dilahirkannya. ${ }^{2,3}$ Infeksi TB pada neonatus dapat terjadi melalui intrauterin, selama persalinan, maupun pasca natal oleh ibu pengidap TB aktif. Kejadian TB kongenital sangat jarang. ${ }^{4,5}$ Di seluruh dunia kasus TB kongenital hanya tercatat 329 kasus. $^{6}$

Gejala klinis TB pada neonatus sulit dibedakan dengan sepsis bakterial umumnya, dan hampir semua kasus meninggal karena keterlambatan diagnosis., ${ }^{4,7}$

\footnotetext{
Alamat Korespondensi:

Dr. Darmawan B Setyanto Sp.A(K)

Divisi Respirologi Departemen Ilmu Kesehatan Anak FKUI-RSCM

Jl. Salemba no. 6, Jakarta 10430. F.

Telepon: 021-3100669. Fax. 021-390 7743

Dr. Bobby S Dharmawan PPDS Ilmu Kesehatan Anak FKUI, Jakarta
}

Deteksi dini TB pada neonatus dan penanganan yang baik pada ibu dengan TB aktif akan memperkecil kemungkinan terjadinya TB kongenital atau TB pada neonatus di kemudian hari. Makalah ini bertujuan untuk membahas tata laksana neonatus dari ibu hamil dengan TB aktif.

\section{Tuberkulosis pada Neonatus}

\section{Epidemiologi}

Berdasarkan laporan WHO, angka kejadian kasus baru TB di dunia mencapai lebih dari 8 juta per tahun. ${ }^{1}$ Indonesia menempati urutan ketiga dengan angka kejadian 450.000 kasus baru per tahun dan angka kematian 175.000 kasus per tahun. ${ }^{2}$ Selama tahun 1989-1990 dari 4.300 persalinan di Rumah Sakit Cipto Mangunkusumo, 150 orang ibu didiagnosis TB paru (prevalens 3,48\%). ${ }^{3}$ Tuberkulosis pada kehamilan merupakan masalah tersendiri karena selain mengenai ibu, juga dapat mengenai bayi yang dikandung atau 
dilahirkannya. ${ }^{2,3}$ Keterlambatan diagnosis TB pada neonatus sering terjadi karena keterlambatan diagnosis TB pada ibu. Oleh karena itu riwayat perjalanan penyakit ibu hamil sangat penting diketahui untuk mencegah keterlambatan diagnosis. Sebagian besar TB pada kehamilan sering kali tanpa gejala yang khas, ${ }^{3}$ maka sekitar 30\% ibu terdiagnosis TB setelah bayi yang dilahirkan di ketahui menderita TB kongenital. ${ }^{8,9}$ Seperti dikutip dari Suwondo dkk, Good menyebutkan gejala klinis TB pada kehamilan berupa batuk (74\%), penurunan berat badan (41\%), demam (30\%), nafsu makan menurun (30\%) dan hemoptisis (19\%). ${ }^{3}$

Infeksi TB perinatal dapat terjadi secara kongenital (pranatal), pada saat persalinan (natal) maupun transmisi pasca natal. Pada tipe kongenital, transmisi terjadi karena penyebaran hematogen melalui vena umbilikalis atau aspirasi cairan amnion yang terinfeksi. Pada tipe natal transmisi dari ibu selama proses persalinan dan pasca natal oleh ibu atau orang dewasa lain secara infeksi droplet. ${ }^{7,10}$

Untuk menegakkan diagnosis TB kongenital, bayi harus terbukti diagnosis TB dan memenuhi salah satu dari kriteria Beitzke yang telah di revisi ${ }^{1,6,8,9,11,12}$ yaitu (1) lesi pada minggu pertama kehidupan, (2) komplek primer hati atau granuloma hati kaseosa, (3) infeksi TB pada plasenta atau pada infeksi traktus genitalia, (4) kemungkinan transmisi pasca natal telah disingkirkan.

Kejadian TB kongenital sangat jarang. Di seluruh dunia sejak tahun 1935 tercatat 329 kasus TB kongenital. ${ }^{6,12}$ Abughali $\mathrm{dkk}^{8}$ melaporkan dari tahun 1980 sampai 1994 hanya terdapat 58 kasus TB kongenital. Hal yang menyebabkan rendahnya angka kejadian TB kongenital adalah (1) Pada wanita dengan tuberkulosis genitalia biasanya mengalami infertilitas. ${ }^{5}$ (2) TB pada orang dewasa umumnya merupakan TB pasca primer yang terlokalisasi di paru, TB primer sistemik jarang terjadi pada orang dewasa. Sedangkan kondisi sistemik dengan penyebaran hematogen diperlukan untuk terjadinya TB kongenital. (3) Adanya sawar plasenta yang dapat mencegah masuknya $M$. tuberculosis ke dalam sirkulasi janin. (4) Tuberkel yang menempel pada plasenta sangat jarang pecah sehingga M.tuberculosis tidak dapat mencapai dan menginfeksi janin. ${ }^{9}$ (5) Kemungkinan terdiagnosis sebagai TB kongenital kecil oleh karena umumnya terdiagnosis sebagai penyakit lain.

Data mengenai TB perinatal di Departemen IKA FKUI RSCM dilaporkan oleh. Rahajoe N. ${ }^{4}$ pada tahun
1996 melaporkan, 26 (16,4\%) dari 171 kasus TB dengan biakan positif adalah anak di bawah usia 1 tahun dengan usia termuda adalah 4 minggu. Hal ini menunjukkan bahwa sumber penularan yang paling mungkin adalah ibu.

\section{Patogenesis}

Pada infeksi intra uteri (pranatal/kongenital) terjadi penyebaran M.tuberculosis secara hematogen oleh ibu TB primer yang sistemik. M.tuberculosis akan menempel dan membentuk tuberkel pada plasenta karena adanya sawar plasenta. Bila tuberkel pecah, akan terjadi penyebaran melalui vena umbilikalis mencapai hati yang mengakibatkan fokus primer di hati serta melibatkan kelenjar getah bening periportal. M.tuberculosis dalam hati dapat masuk ke dalam peredaran darah kemudian mencapai paru membentuk fokus primer dalam bentuk dorman., ${ }^{911,13}$ Tuberkel pada plasenta yang pecah tersebut dapat pula menginfeksi cairan amnion. Cairan amnion yang terinfeksi M.tuberculosis terhisap oleh janin selama kehamilan sehingga kuman dapat mencapai paru dan menyebabkan fokus primer di paru. Namun bila cairan amnion tersebut tertelan, kuman akan mencapai usus yang menyebabkan fokus primer di usus. ${ }^{9}$

Infeksi TB pada neonatus yang terjadi saat persalinan (natal), dapat terjadi karena tertelan atau terhisapnya cairan amnion yang terinfeksi M.tuberculosis oleh neonatus saat proses persalinan. Pada penularan ini kuman yang teraspirasi dapat menyebabkan fokus primer di paru atau di usus. ${ }^{9}$ Penularan infeksi TB pasca natal merupakan penularan TB pada neonatus yang paling sering ${ }^{1}$, yaitu melalui inhalasi udara (droplet infection) oleh ibu atau orang dewasa lain penderita TB aktif di sekitar neonatus. Kuman TB mencapai alveolus paru terutama pada lobus tengah dan lobus bawah yang kaya akan oksigen sehingga umumnya fokus primer akan terdapat di sini, walaupun semua lobus bisa saja menjadi fokus primer. ${ }^{5,7}$

\section{Manifestasi klinis}

Manifestasi klinis TB kongenital dapat timbul segera setelah lahir namun paling sering pada minggu kedua dan ketiga kehidupan. ${ }^{5,9}$ M.tuberculosis kurang dapat berkembang pada lingkungan intra uterin dengan 
kadar oksigen yang rendah. Dengan bertambahnya usia bayi setelah lahir, kadar oksigen pun meningkat mengakibatkan pertumbuhan bakteri yang cepat. ${ }^{10}$

Gejala klinis TB kongenital sulit dibedakan dengan sepsis bakterial pada umumnya. Oleh sebab itu sering terjadi keterlambatan diagnosis dan pada akhirnya menyebabkan kematian. Gejala yang paling sering ditemukan adalah distres pernapasan, hepatosplenomegali dan demam ${ }^{8}$ (Tabel 1). Gejala lain seperti prematuritas, berat lahir rendah, toleransi minum yang buruk, letargi, kejang, ikterus, limfadenopati, lesi kulit, dan cairan pada telinga juga dilaporkan. ${ }^{1,4,5,8}$ Pejham $\mathrm{dkk}^{13}$ melaporkan 1 kasus TB kongenital dengan facial nerve palsy karena infeksi pada sistem saraf pusat.

Tuberkulosis yang didapat pasca natal memiliki gejala yang sama dengan TB pada anak, seperti berat badan turun tanpa sebab, gagal tumbuh, demam lama dan berulang, pembesaran kelenjar getah bening multipel, batuk lama, atau diare persisten. ${ }^{1,5}$

Tabel 1. Gejala klinis pada 58 kasus tuberkulosis kongenital

\begin{tabular}{lcc}
\hline & Jumlah & $\%$ \\
\hline Distres pernapasan & 44 & 76 \\
Hepatomegali dan/tanpa splenomegali & 38 & 65 \\
Demam & 33 & 57 \\
Limfadenopati & 19 & 33 \\
Toleransi minum buruk & 18 & 31 \\
Letargi & 16 & 30 \\
Distensi abdomen & 15 & 26 \\
Gagal tumbuh & 9 & 15 \\
Cairan pada telinga & 9 & 15 \\
Ruam kulit & 5 & 9 \\
Funduskopi abnormal & 4 & 7 \\
Ikterus & 4 & 7 \\
Kejang & 3 & 5 \\
B.a.b berdarah & 3 & 5 \\
Asites & 3 & 5 \\
\hline
\end{tabular}

Dikutip dari Abughali N, Annable W, Kumar M. Congenital Tuberculosis. Pediatr Infect Dis J, 1994;13:738-41

\section{Pemeriksaan penunjang}

Uji tuberkulin pada neonatus sering negatif karena penyakit berat atau sistem imun neonatus yang masih imatur. Pemeriksaan bakteri tahan asam (BTA) dan biakan kuman dapat menunjukkan hasil positif dari bilasan lambung, cairan telinga, serta biopsi hati, kelenjar getah bening, dan sumsum tulang. ${ }^{9}$ Gambaran foto toraks neonatus dengan TB sering menunjukkan kelainan; sebagian besar terdapat gambaran milier namun dapat pula ditemukan infiltrat paru dan pembesaran kelenjar getah bening hilus. Beberapa neonatus yang memiliki gambaran foto yang normal yang kemudian menjadi abnormal bersamaan dengan progresivitas penyakit., ${ }^{5,9}$ Pada pemeriksaan ultrasonografi abdomen dapat ditemukan pembesaran dan lesi fokal pada hati dan limpa, ekogenisitas yang heterogen, pembesaran kelenjar getah bening multipel serta cairan debris peritoneum. ${ }^{10}$ Gambaran histopatologi plasenta dapat ditemukan granuloma kaseosa dengan BTA. ${ }^{6,8,14}$ Adanya tuberkel pada plasenta belum dapat memastikan bahwa bayi menderita TB kongenital, karena tuberkel pada plasenta dapat utuh (tidak pecah).

\section{Diagnosis dan tata laksana}

Tata laksana TB pada neonatus mencakup beberapa aspek yaitu ibu, bayi yang dilahirkan dan lingkungan keluarga. Ibu yang terdiagnosis TB berdasarkan pemeriksaan fisik, radiologik dan bakteriologik menjelang atau saat persalinan harus diisolasi. ${ }^{9}{ }^{915}$ Bila ibu telah didiagnosis TB aktif pada kehamilan, pengobatan anti tuberkulosis (OAT) langsung diberikan tanpa mengesampingkan efek samping OAT pada janin. ${ }^{3}$ Obat yang rekomendasi oleh WHO dan Perhimpunan Dokter Paru Indonesia (PDPI) yaitu kombinasi rifampisin, isoniasid, pirazinamid dan etambutol. Regimen OAT sama seperti pada kasus TB lainnya kecuali streptomisin tidak diberikan karena bersifat teratogenik. Pada ibu yang telah cukup mendapat pengobatan sebelumnya selama kehamilan, pada umumnya selama persalinan proses tuberkulosis sudah tenang. ${ }^{2,3}$

Dokter ahli kebidanan bersama dokter anak harus saling berdikusi sebelum bayi dilahirkan. ${ }^{11}$ Setelah bayi dilahirkan segera lakukan pemeriksaan patologi anatomi plasenta dan pemeriksaan mikrobiologi dari darah vena umbilikalis untuk mencari gambaran tuberkel dan atau kuman TB. ${ }^{5,9}$

Setelah ibu diisolasi, evaluasi klinis dan foto toraks dilakukan pada neonatus. Gejala klinis TB kongenital sulit dibedakan dengan sepsis bakterial pada umumnya. ${ }^{8}$ Sehingga bila gejala klinis sesuai dengan sepsis bakterialis 
dapat diberikan terapi kombinasi anti tuberkulosis dan antibiotik. Pemantauan klinis pada neonatus meliputi apakah terdapat prematuritas, berat lahir rendah, distres pernapasan, hepato-splenomegali, demam, letargi, toleransi minum yang buruk, gagal tumbuh, atau distensi abdomen. ${ }^{5,9}$ Bila pada pemantauan klinis terdapat limfadenopati, lesi di kulit, atau sekret pada telinga dilakukan pemeriksaan mikrobiologi dan atau patologi anatomi. Bila didapatkan hepatomegali selama pemantauan klinis dilakukan pemeriksaan USG abdomen, dan bila ditemukan kompleks primer maka dilanjutkan dengan biopsi hati. Pemantauan klinis kadang-kadang perlu dilakukan dalam jangka waktu tertentu. Gejala klinis TB kongenital dapat timbul segera setelah lahir atau hingga minggu kedua dan ketiga kehidupan. ${ }^{5,9}$

Bila pada neonatus terdapat gejala TB maka diagnosisnya adalah TB perinatal dan terapi TB langsung diberikan. Terapi yang dianjurkan adalah isoniasid dosis $5-10 \mathrm{mg} / \mathrm{kgBB} / \mathrm{hari}$, rifampisin dosis $10-15 \mathrm{mg} / \mathrm{kgBB} / \mathrm{hari}$ dan pirazinamid dosis $25-35 \mathrm{mg} /$ $\mathrm{kgBB} /$ hari. ${ }^{5,9}$ Lakukan pemeriksaan bilas lambung sebelum pemberian terapi. Setelah terapi TB selama 1 bulan (usia 1 bulan) lakukan pemeriksaan uji tuberkulin. Namun pada neonatus dengan gejala klinis TB dan didukung oleh satu atau lebih pemeriksaan penunjang (foto toraks, patologi anatomi plasenta dan mikrobiologis darah v.umbilikalis) maka dapat langsung diobati selama 6 bulan tanpa pemerikaan uji tuberkulin.

Apabila pada usia 1 bulan uji tuberkulin positif maka diagnosis TB ditegakkan dan diberikan terapi TB selama 6 bulan disertai pemeriksaan foto toraks dan bilas lambung. Namun bila hasil uji tuberkulin negatif, masih mungkin TB karena faktor imunitas yang imatur pada neonatus. ${ }^{9}$ Dalam hal ini terapi TB diteruskan disertai pemeriksaan tuberkulin pada usia 3 bulan. Apabila hasil uji tuberkulin pada usia 3 bulan positif maka diagnosis TB ditegakkan dan diberikan terapi TB selama 6 bulan. Namun apabila hasilnya negatif maka diagnosis bukan TB dan terapi TB dihentikan.Selain mendapat terapi TB, pemberian nutrisi harus adekuat. Bayi dipisahkan selama minimal 2 minggu pemberian terapi TB pada ibu, namun ASI tetap dapat diberikan. Kandungan OAT di dalam ASI pada ibu yang mendapat terapi TB hanya dalam jumlah yang kecil dan tidak berpotensi menimbulkan infeksi pada bayi. ${ }^{1,2,7,9}$ Selain itu pemantauan peningkatan berat badan, tanda vital, dan keluhan lain harus dilakukan dengan ketat. ${ }^{5}$

Apabila neonatus lahir dari ibu TB aktif namun pemeriksaan klinis dan penunjang dalam batas normal, maka neonatus tetap berpotensi untuk terinfeksi M.tuberculosis. Tata laksana awal adalah pemberian profilaksis primer INH dengan dosis 5$10 \mathrm{mg} / \mathrm{kgBB} /$ hari selama 1 bulan kemudian dilakukan uji tuberkulin untuk mengetahui apakah pasien telah terinfeksi. ${ }^{4,5,9,15}$ Apabila setelah 1 bulan uji tuberkulin positif maka diagnosis TB dapat ditegakkan dan diberikan terapi TB selama 6 bulan disertai pemeriksaan foto toraks dan bilas lambung. ${ }^{9,15}$ Namun bila setelah 1 bulan uji tuberkulin negatif maka pemberian profilaksis primer INH diteruskan sampai 3 bulan kemudian dilakukan uji tuberkulin untuk mengetahui apakah pasien telah terinfeksi. Bila setelah 3 bulan uji tuberkulin tetap negatif dan telah dibuktikan tidak ada sumber penularan lagi maka profilaksis primer INH dapat dihentikan. Namun bila positif, harus dinilai klinis dan pemeriksaan penunjang. Bila terdapat kelainan maka didiagnosis TB dan diberikan terapi TB selama 6 bulan. ${ }^{9,15}$ Apabila pemeriksaan tidak mendukung TB, maka diberikan profilaksis sekunder selama 6-12 bulan. ${ }^{9,15}$ Pemberian BCG hanya dapat dilakukan apabila bayi belum terinfeksi $M$.tuberculosis yaitu pada saat 3 bulan dan uji tuberkulin negatif. ${ }^{4,9}$

Tata laksana terhadap lingkungan meliputi lingkungan keluarga. Harus dicari adanya sumber penularan atau keluarga lain yang tertular melalui pemeriksaan klinis, laboratorium maupun radiologis. ${ }^{2,9}$

\section{Prognosis}

Prognosis TB kongenital biasanya lebih buruk dari TB didapat pasca natal. Komplikasi TB pada neonatus adalah koagulasi intravascular diseminata, meningitis, gagal napas, perforasi usus dan syok sepsis. ${ }^{11,16-20}$ Hampir 50\% dari kasus TB kongenital dilaporkan meninggal, meskipun dengan penanganan yang intensif. Hal ini disebabkan karena keterlambatan diagnosis dan komplikasi. ${ }^{7,8}$ Oleh karena itu deteksi dini ibu dan neonatus dengan TB serta penanganan yang baik pada neonatus sangat penting untuk memperkecil angka kematian TB pada neonatus. 
Sari Pediatri, Vol. 6, No. 2, September 2004

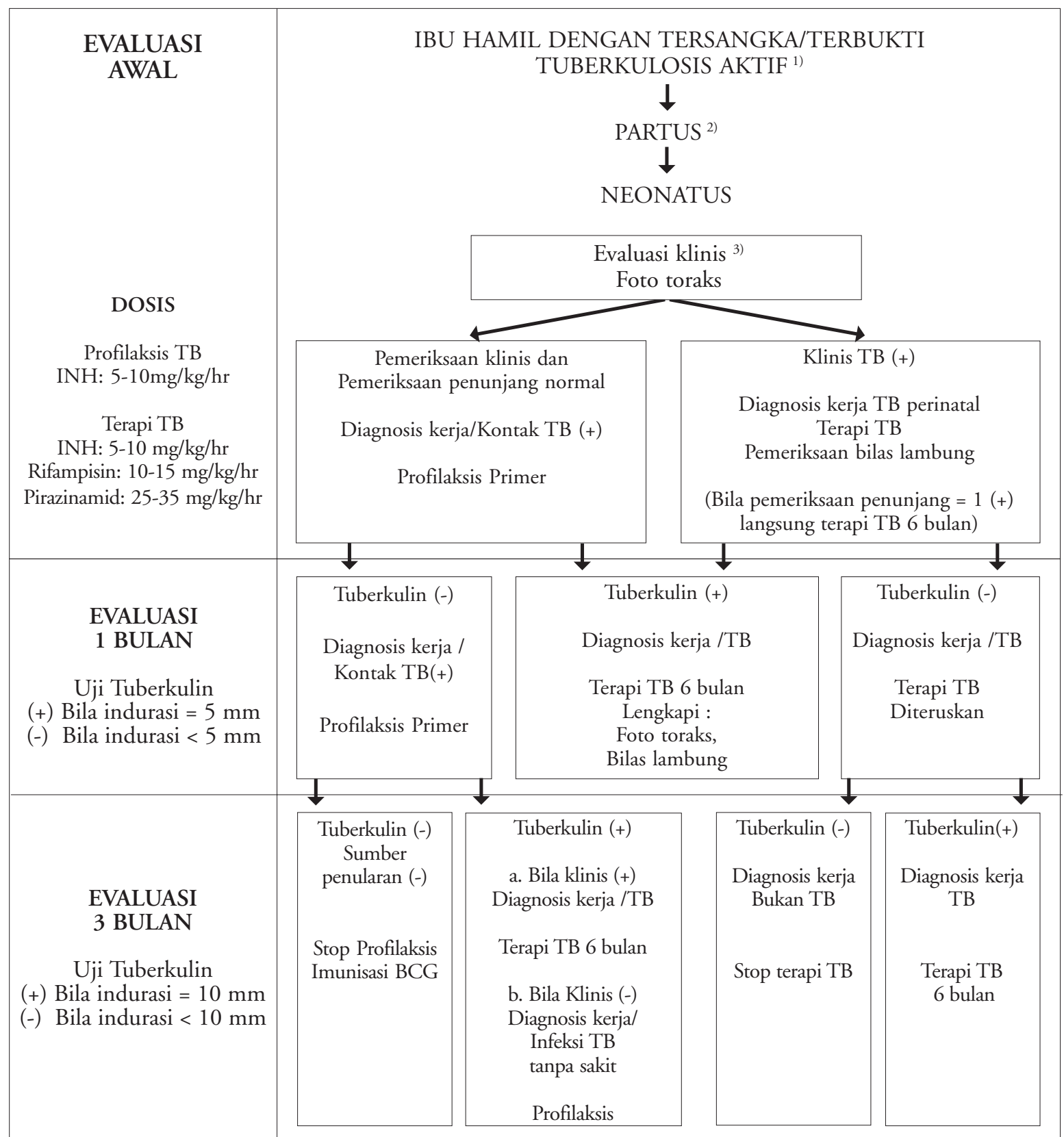

Gambar 1. Skema diagnosis dan tata laksana neonatus dari ibu hamil dengan tuberkulosis aktif. Departemen Ilmu Kesehatan Anak RSCM 2004

KETERANGAN :

1) Buktikan diagnosis TB pada ibu secara klinis, radiologis dan mikrobiologis. Bila ibu telah didiagnosis TB aktif maka diobati dengan OAT.

Bayi dipisahkan sampai dengan minimal 2 minggu pemberian OAT pada ibu, namun ASI tetap dapat diberikan.

2) Lakukan pemeriksaan plasenta (PA, makroskopik \& mikroskopik), darah v.umbilikalis (Mikrobiologi=BTA \& biakan TB).

3) Klinis: Prematuritas, berat lahir rendah, distres pernapasan, hepato-splenomegali, demam, letargi, toleransi minum buruk, gagal tumbuh, distensi abdomen.

- Bila klinis sesuai sepsis bakterialis dapat diberikan terapi kombinasi.

- Bila pada evaluasi klinis terdapat limfadenopati, lesi kulit atau ear discharge lakukan pemeriksaan mikrobiologi dan/atau PA.

- Bila dalam perjalanan klinis terdapat hepatomegali lakukan pemeriksaan USG abdomen, jika ditemukan kompleks primer lanjutkan dengan biopsi hati.

4) Imunisasi BCG sebaiknya tidak diberikan sebelum usia 3 bulan 


\section{Daftar Pustaka}

1. Batra V, Ang Jocelyn. Tuberculosis. Didapat dari: http:/ /www.emedicine.com/ped/topic2321.htm. Diakses tanggal 17 Februari 2004

2. Perhimpunan Dokter Paru Indonesia. Tuberkulosis paru. Dalam Konferensi Kerja VIII Perhimpunan Dokter Paru Indonesia. Jakarta. November 1998

3. Suwondo A. Tuberkulosis paru pada kehamilan. Dalam: Suwondo A, Nelwan RHH, Kurniawan L, Utji R. Penyunting Simposium Penanggulangan Infeksi dalam Kehamilan. Jakarta. Balai Penerbit FKUI, 1991.h.49-57

4. Rahajoe NN. Tatalaksana Bayi dari Ibu Pengidap Tuberkulosis. Dalam: Marwoto W, Rachimhadhi T, Pusponegoro TS. Penyunting. Penanganan terpadu Infeksi Perinatal. Jakarta Balai Penerbit FKUI.1996:12-6

5. Starke JR, Munoz F. Tuberculosis In: Behrman. Nelson Textbook of Pediatrics. Edisi ke-16. Philadelphia. WB Saunders Company, 2000.h.886-97

6. Anderson GD. Tuberculosis in pregnancy. Seminars in Perinatology 1997;21:328-35

7. Adis International Editors. Managing pregnant women with tuberculosis. J Paed Obst Gynaecol 1997;Jan/ Feb:25-8

8. Abughali N, Annable W, Kumar M. Congenital tuberculosis. Pediatr Infect Dis J 1994;13:738-41

9. Starke JR. Tuberculosis an old disease but a new threat to the mother, fetus and neonate. Dalam: Stoll BJ, Weisman LE. penyunting. Clinics in Perinatology. Philadelphia. WB Saunders Company, 1997.h.107-23
10. Akinbami LJ, Selby DM, Slonim AD. Hepatosplenomegaly and pulmonary infiltrates in an Infant. J Pediatr 2001;139:124-9

11. Mazade MA, Evans EM, Starke JR. Congenital tuberculosis presenting as sepsis syndrome: Case report and review of the literature. Pediatr Infect Dis J 2001;20:439-42

12. Damian RF, Arredondo-Garcia. Pregnancy and tuberculosis: Influence of treatment on perinatal Outcome. Am J Perinatol 1998;15:303-5

13. Pejham S, Altman R, Li KL. Congenital tuberculosis with facial nerve palsy. Pediatr Infect Dis J, 2002;21:1085-6

14. Wise GJ, Marella VK. Genitourinary manifestation of tuberculosis. Urol Clin North Am 2003;30:111-21

15. AAP 2000 Red Book: Report of committee on infectious Disease. Edisi ke-25. American Academy of Pediatrics, 2000.h.594-613

16. Hamadeh MA, Glassroth J. Tuberculosis and pregnancy. Hougen TJ. Digitalis use in children: an Chest 1992;101:1114-20

17. Anuntaseree W, Suntotnlohanakul S, Mintarnun W. Disseminated tuberculosis in a 2-months-old infant.Pediatr Pulmonol 1992;13:255-8

18. Foo AL, Tan KK, Chay OM. Congenital tuberculosis. Tubercle and Lung Dis 1993;74:59-61

19. Vucicevic Z, Suskovic T, Ferencic Z, A female patient with tuberculosis polyseroritis and congenital tuberculosis in her newborn child. Tubercle and Lung Dis 1995:76:460-2

20. Agrawal RL, Rehman H. Congenital military tuberculosis with intestinal perforations. Tubercle and Lung Dis $1995 ; 76: 468-9$ 